\title{
Tecido cerebral ectópico na órbita: relato de dois casos
}

\author{
Ectopic brain tissue in the orbit: twocase reports
}

\author{
Josilene de Carvalho Soares Liarth ${ }^{(1)}$ \\ Mansueto Martins Magalhães ${ }^{(2)}$ \\ João Orlando Ribeiro Gonçlves ${ }^{(3)}$ \\ Joaquim Marinho de Queiroz ${ }^{(4)}$ \\ Anne Leite Magalhães Sampaio ${ }^{(5)}$
}

\begin{tabular}{|l|}
\hline \multicolumn{1}{|c|}{ RESUMO } \\
\hline Tecido cerebral na órbita, tendo continuidade com o conteúdo \\
intracraniano, é relativamente incomum. Tecido cerebral isolado na \\
órbita, entretanto, é muito mais raro. No presente trabalho são apre- \\
sentados dois casos de tecido cerebral ectópico na órbita, com cisto \\
ependimal. São analisadas as similaridades e diferenças com outros \\
casos da literatura, bem como as dificuldades no diagnóstico desta \\
malformação. Não conhecemos nenhum caso descrito na literatura \\
nacional.
\end{tabular}

Descritores: Tecido heterotópico; Coristoma/patologia; Doenças orbitárias/patologia; Cérebro; Relato de Caso; Epêndima/patologia.

\section{INTRODUÇÃO}

A heterotopia cerebral tem sido definida como a ocorrência de tecido neural normal, fora da cavidade craniana ou espinal, sem continuidade com o cérebro ou meninges ${ }^{1}$. A localização mais freqüentemente registrada é a região nasal. Outros locais incluem a faringe, língua, palato mole, bochecha, pele, leptomeninges, olho (em associação com dermóide límbico ${ }^{2}$ e crânio (separado do cérebro por osso e/ou dura-máter). Tecido cerebral isolado na órbita, de acordo com a maioria dos autores, é muito raro.

Em 1980, Vaquero et al. ${ }^{3}$ descreveram um paciente com hamartoma glial intra-orbitário com extensão extradural intracaniana. Em 1986, Newman et al. ${ }^{1}$ registraram um caso de coristoma glial intra-orbitário. Wilkins et al. ${ }^{4}$, em 1987, relataram um terceiro caso de tecido cerebral ectópico na órbita com conteúdo líquido. Posteriormente, Elder et al. ${ }^{5} \mathrm{em} 1989$, Hingorani et al. ${ }^{6}$ em 1997, Scheiner et al. ${ }^{7}$ em 1999 e Harmon et al. ${ }^{8}$ em 2000, também registraram casos de tecido cerebral ectópico na órbita. Não se conhece nenhum caso descrito na literatura oftalmológica nacional.

Os espécimes de cérebro ectópico geralmente consistem em células gliais (principalmente astrócitos fibrilares) e tecido conjuntivo fibroso. Raramente contém tecido ependimal, meníngico ou retínico ${ }^{1}$.

Ao nascimento, as crianças geralmente apresentam proptose, com expansão da órbita unilateralmente, podendo apresentar outras malformações associadas. Outras vezes, apresentam anoftalmia ou estruturas oculares primitivas ou cistos 7,9 .

Por ser um malformação congênita, o diagnóstico pode ser feito precocemente através de biópsia pré-natal da massa orbiária (biópsia de tecido fetal) ${ }^{6}$ e a excisão da lesão, na infância, posteriormente. O estudo tomográfico da órbita por sua vez pode demonstrar, entre outros achados, a presença ou ausência de um defeito ósseo, caracterizando a continuidade ou ectopia, respectivamente, da massa orbitária com o cérebro. 


\section{RELATODOSCASOS}

\section{Caso1}

W.M.S.C., masculino, melanodermo, 10 meses, procurou a clínica oftalmológica do Hospital Getúlio Vargas (HGV) Teresina - PI, em novembro/95, com história de tumoração no olho esquerdo, desde o nascimento, que vinha aumentando progressivamente de tamanho.

A criança era produto de uma gestação normal, havia nascido de parto normal, a termo, e era aparentemente sadia. Não havia casos semelhantes na família.

Ao exame, apresentava formação aparentemente cística, medindo $20 \times 20 \mathrm{~mm}$, ocupando toda cavidade orbitária esquerda, coloboma das porções medial e lateral da pálpebra inferior, ângulo medial desviado para baixo, ectopia de ângulo lateral e apêndice cutâneo próximo ao ângulo externo, não se observava o bulbo ocular. O olho e anexos oculares contralaterais eram normais.

Foram solicitadas radiografia $(\mathrm{Rx})$, ultra-sonografia e tomografia computadorizada (TC) das órbitas e do crânio. A mãe da criança viajou com ela para sua cidade, não tendo realizado os exames.

A criança retornou ao serviço, com a lesão expansiva da órbita (LEO) no olho esquerdo, em maio/96.

O paciente apresentava então, uma protrusão do conteúdo orbitário de consistência amolecida, elástica, indolor à palpação, desvio da rima palpebral com exposição da conjuntiva tarsal inferior. Não se observava o bulbo ocular (Figura 1).

$\mathrm{O} \mathrm{Rx}$ das órbitas mostrou tumoração de partes moles na órbita esquerda com envolvimento ósseo da parede súperoexterna da órbita e a TC evidenciou lesão expansiva tumoral sólida, irregular, localizada na porção posterior do bulbo ocular, estendendo-se posteriormente e ocupando o espaço intracônico. Não foi possível realizar a ultra-sonografia.

Com a hipótese diagnóstica de cisto orbitário congênito, a criança foi submetida a procedimento cirúrgico, excisão do cisto orbitário, sob anestesia geral, em 14/06/96.

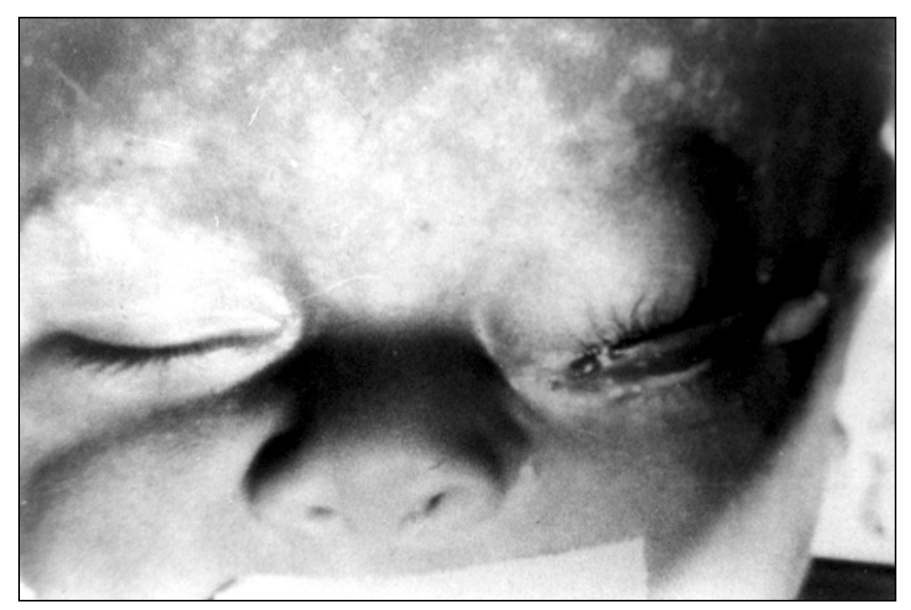

Figura 1 - Paciente do caso 1
O exame histopatológico da peça mostrou: cavidade cística revestida internamente por células cubóides parcialmente atróficas, lembrando células ependimais. Externamente o cisto estava circundado por células gliais (astrócitos) separadas por malha fibrilar neuroglial. Conclusão histopatológica: tecido neuroglial encefálico ectópico na cavidade orbitária circundando cisto ependimal (Figura 2).

$\mathrm{O}$ estudo imuno-histoquímico mostrou a presença de proteína ácida fibrilar glial (GFAP).

A criança não mais retornou ao serviço para reavaliação.

\section{Caso 2}

L.A.S., feminino, feodermo, 4 meses, procurou a clínica oftalmológica do H.G.V. - Teresina - PI em fevereiro/97 com história de tumoração no olho esquerdo desde o nascimento. Não havia relato de inflamação ou crescimento da lesão.

A criança era o $4^{\circ}$ filho de uma prole de quatro, sendo produto de gestação sem complicações, nascida de parto normal, a termo e não apresentava outras anomalias congênitas.

A mãe referia que um irmão da paciente apresentava "olho branco" desde o nascimento porém o mesmo nunca havia sido submetido a exame oftalmológico.

Ao exame, a paciente apresentava formação protrusa de consistência amolecida, medindo mais ou menos $30 \times 25 \mathrm{~mm}$ ocupando toda cavidade orbitária esquerda e abaulando a pálpebra inferior; entrópio da pálpebra superior; ponto lacrimal superior permeável; fundos de saco superior e inferior apresentando margens levemente evertidas pela distensão causada pela massa, conjuntiva palpebral exposta e ceratinizada; velamento do ponto lacrimal inferior. Não se observava o bulbo ocular. O olho direito era normal. A criança apresentava nistagmo.

A TC do crânio foi normal e a das órbitas evidenciou LEO predominantemente cística do bulbo ocular esquerdo, com imagens radio densas sugestivas de cálcio de permeio.

Sob a hipótese diagnóstica de olho cístico congênito, a

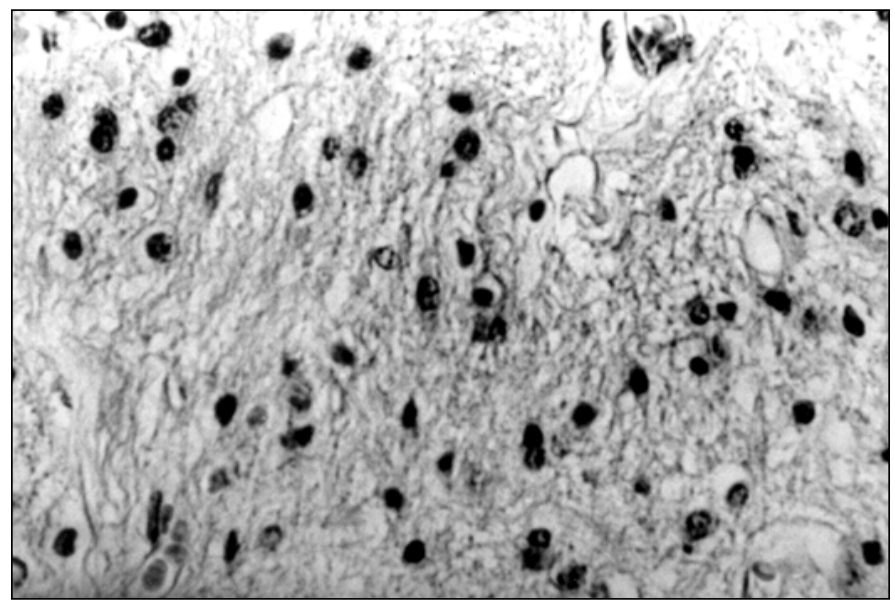

Figura 2 - Tecido cerebral ectópico na órbita. Astrócitos separados por matrix neuroglial fibrilar. H-E x 40. 
criança foi então submetida a procedimento cirúrgico, sob anestesia geral, em 18/03/97. Foi realizado punção do cisto com retirada de mais ou menos $3 \mathrm{ml}$ de líquido discretamente amarelado e em seguida feito incisão da conjuntiva e cápsula bulbar, próximo ao fundo de saco inferior, no sentido da rima palpebral; divulsão da cápsula bulbar até exposição do cisto e excisão do mesmo. Sua localização era principalmente inferior, estava muito aderido superiormente a um bulbo ocular de tamanho muito reduzido, o qual foi conservado na órbita. Durante a dissecção houve ruptura involuntária do cisto. Foi colocado dreno de Penrose $\mathrm{n}^{\mathrm{o}} 1 \mathrm{em}$ face do grande espaço vazio resultante. O septo orbitário foi apenas reorganizado, mas não suturado. A cápsula bulbar e a conjuntiva foram suturadas em planos separados com vicryl 6-0. Foi colocado um modelador de cavidade e feita blefarorrafia provisória com seda 6-0. A peça mediu $25 \times 20 \mathrm{~mm}$, apresentando conteúdo líquido, discretamente amarelado, límpido, com volume total de mais ou menos $6 \mathrm{ml}$.

Após o procedimento cirúrgico a hipótese diagnóstica foi microftalmo com cisto.

$\mathrm{O}$ estudo bioquímico do líquido puncionado demonstrou ausência de células, glicose $=37 \mathrm{mg} / \mathrm{dl}$ e proteínas $=171 \mathrm{mg} / \mathrm{dl}$.

O histopatológico evidenciou tecido neuroglial encefálico circundando um cisto de aspecto ependimal, com parede interna revestida por células cubóides, vasos abundantes e glia (hamartoma glial astrocítico); tecido neuroglial ectópico com trabéculas de tecido conectivo interpondo-se ao tecido neural. Conclusão histopatológica: tecido neuroglial encefálico e cisto ependimal ectópico na cavidade orbitária (Figura 3).

O estudo imuno-histoquímico mostrou a presença de GFAP.

A criança retornou à clínica oftalmológica em fevereiro/99, mais ou menos 2 anos após o procedimento cirúrgico, sem história de recidiva da lesão. A TC das órbitas demonstrou microftalmia a esquerda com material sólido amorfo e calcificação, espessamento do nervo óptico, aumento das partes moles.

Em ambos os casos descritos, devido à condição sócio-

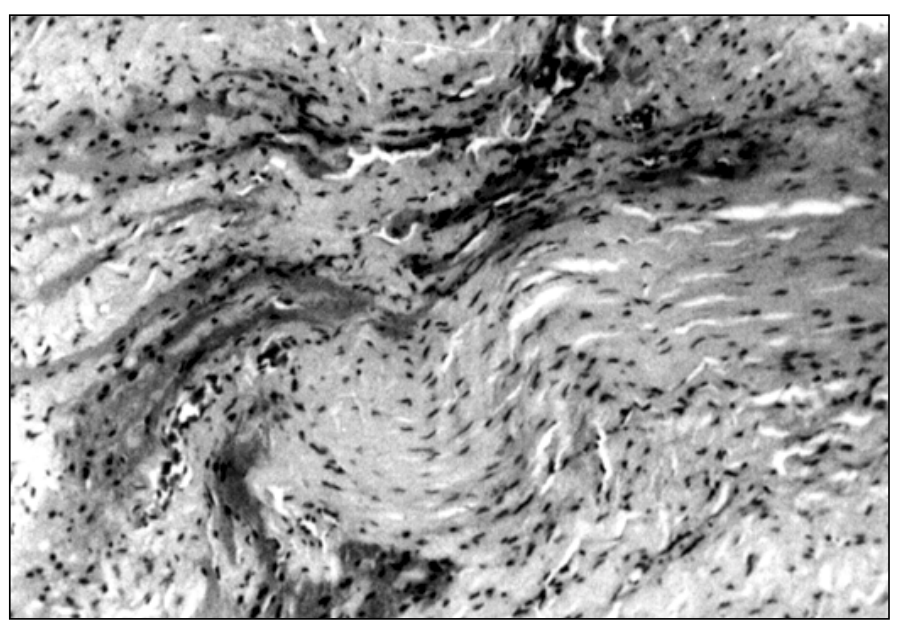

Figura 3 - Tecido cerebral ectópico na órbita. Trabéculas de tecido conectivo subdividindo o tecido neural. H-E x 40. econômica dos pacientes, não foi possível realizar ressonância magnética, uma vez que os serviços de saúde da rede pública local à época do diagnóstico, não realizavam este exame.

\section{DISCUSSÃO}

As cefaloceles são definidas como a protrusão do conteúdo craniano através de uma abertura no crânio, mantendo comunicação com o espaço subaracnóide ou sistema ventricular ${ }^{1}$. Elas são classificadas pelo tipo de tecido herniado, bem como pela localização da comunicação intracraniana.

Tecido cerebral ectópico, por sua vez, é definido como a ocorrência de tecido neural normal, fora da cavidade craniana ou espinal, sem continuidade com o cérebro ou meninges ${ }^{1}$.

$\mathrm{O}$ tecido cerebral ectópico pode ter a mesma apresentação, curso clínico, tratamento e constituintes neurais das cefaloceles, porém no primeiro, nenhuma conexão com o sistema nervoso central é demonstrável ${ }^{9}$.

As localizações do tecido cerebral ectópico incluem a região nasal (mais freqüente), faringe, língua, palato mole, bochecha, pele, leptomeninges, olho (em associação com dermóide límbico) ${ }^{2}$ e crânio (separado do cérebro por osso ou dura-máter). Tecido cerebral isolado na órbita é muito raro.

Casos de tecido cerebelar na órbita têm sido descritos na literatura ${ }^{10-11}$.

As principais teorias relacionando a patogênese do tecido cerebral ectópico são: 1- herniação do tecido cerebral fetal na embriogênese, de maneira semelhante ao desenvolvimento das encefaloceles, com subseqüente sequestração e descontinuidade; 2- restos neurais embrionários com um potencial para diferenciação em diferentes tipos de tecido neural; 3desenvolvimento preferencial de uma camada germinativa de um teratoma dentro da linha das células neurais e 4- astrocitomas verdadeiros. A teoria mais aceita é a primeira.

Os espécimes de cérebro ectópico geralmente consistem em células gliais (principalmente astrócitos fibrilares) e tecido conjuntivo fibroso. Raramente contêm tecido ependimal, meníngico ou retínico ${ }^{1}$. Os pacientes deste estudo apresentaram LEO com cavidade cística, revestida internamente por células cubóides, compatíveis com células ependimais e externamente por células gliais (astrócitos) separadas por malha fibrilar neuroglial. Não foi observado músculo estriado, como no caso do paciente descrito por Newman e col. ${ }^{1}$. Embora a TC do segundo paciente deste estudo tenha demonstrado imagens radio densas sugestivas de cálcio de permeio, o exame histopatológico não demonstrou corpos calcificados. O tecido neural pode se edemaciar e se degenerar, aparecendo depósitos de cálcioo ${ }^{3,9}$.

Os pacientes deste estudo também apresentaram LEO com conteúdo líquido. O primeiro paciente não retornou para seguimento e o segundo, não apresentou qualquer recidiva durante o período de observação, contrariamente ao caso descrito par Walkins et al. ${ }^{4}$, onde foi observado persistente 
acúmulo de líquido, cuja origem os autores não conseguiram determinar.

As TCs dos pacientes não demonstraram continuidade intracraniana. Nenhum defeito ou comunicação com o cérebro foi observado durante a exploração cirúrgica. Portanto, nenhuma craniotomia foi sugerida.

O primeiro paciente apresentou malformações como coloboma palpebral, alterações do ângulo e apêndice cutâneo e ambos, apresentaram microftalmo, como descrito na literatura ${ }^{9-10}$.

Os pacientes do estudo em questão, não tiveram o bulbo ocular observado à inspeção e a hipótese diagnóstica inicial foi de olho cístico congênito, malformação ocular congênita rara ${ }^{12}$. Durante a exploração cirúrgica, a observação de um pequeno bulbo ocular, orientou o diagnóstico para microftalmo com cisto. O estudo histopatológico, porém, demonstrou a natureza da lesão. O diagnóstico clínico apresenta dificuldades em virtude da similaridade na apresentação e na localização da lesão com inúmeras outras.

Não se pode deixar de observar a grande similaridade entre os casos aqui registrados e outros da literatura, ${ }^{1-4,7-8,10}$ quanto à lateralidade da LEO, com envolvimento quase exclusivo da órbita esquerda.

O fato das lesões, em ambos os casos, não terem apresentado mistura de tecidos e o tecido cerebral ser de aspecto citológico normal, bem como a ausência de recidivas no período observado, sugeriu o caráter benigno delas. Isto, portanto, permitiu conduta expectante posteriormente ao primeiro procedimento. A ausência de recidiva no segundo caso, também sugeriu ter sido completa a remoção da massa orbitária.

\section{ABSTRACT}

Brain tissue in the orbit in continuation with intracranial contents is unusual. However, isolated brain tissue in orbit, is much rarer.
In the present research, two cases of ectopic brain tissue in the orbit with ependymal cyst are reported.

Similarities with and differences between other cases reported in the literature are analyzed, as well as the difficulties of the diagnosis of their malformation. There are not many many cases of ectopic brain tissue reported in the literature.

Keywords: Choristoma; Orbital diseases/pathology; Brain; Case report; Ependyma/pathology.

\section{REFERÊNCIAS}

1. Newman NJ, Miller NR, Green WR. Ectopic brain in the orbit. Ophthalmology 1986;93:268-72.

2. Hutchison DS, Green WR, Iliff CE. Ectopic brain tissue in a limbal dermoid associated with a scleral staphyloma. Am J Ophthalmol 1973;76:984-6.

3. Vaquero J, Cabezudo JM, Leunda G, Carrilo R, Bravo G. Intraorbital and intracranial glial hamartoma: case report. J Neurosurg 1980;53:117-20.

4. Wilkins RB, Hofman RJ, Byrd WA, Font RL. Heterotopic brain tissue in the orbit. Arch Ophthalmol 1987;105:390-2.

5. Elder JE, Chow CW, Holmes AD. Heterotopic brain tissue in the orbit: case report.Br J Ophthalmol 1989;73:928-31.

6. Hingorani M, Mannor G, Vardy SJ, Luthert P, Nicolaides KH, McCartney AC, Rose GE, Aclimandos W. Prenatal diagnosis of orbital heterotopic brain tissue. J Pediatr Surg 1997;32:1348-50.

7. Scheiner AJ, Frayer WC, Rorke LB, Heher K. Ectopic brain tissue in the orbit. Eye 1999;13(Pt 2):251-4

8. Harmon HL, Gossman MD, Buchino JJ, Eberly SM, Roberts DM, Fishman $\mathrm{PH}$. Orbital ganglioglioma arising from ectopic neural tissue. Am J Ophthalmol 2000;129:109-11.

9. Henderson JW, Campbell RJ, Farrow GM, Garrity JW. Orbital Tumors. 3rd ed. New York: Raven Press; 1994.

10. Call NB, Baylis HI. Cerebellar heterotopia in the orbit. Arch Ophthalmol 1980;98:717-9.

11. Kagotani Y, Takao K, Nomura K, Imai Y, Hashimoto K. Intraorbital cerebellar heterotopia associated with Chiari I malformation. J Pediatr Ophthalmol Strabismus 1996;33:262-5.

12. Duke-Elder, S. Congenital deformities In: System of Ophthalmology. London: Kimpton; 1964. p. 451-3.

\title{
IV Congresso da Sociedade Brasileira de Retina e Vítreo
}

\section{Imperial Othon Hotel - Fortaleza - CE}

\author{
27 a 29 de Abril de 2.001
}

INFORMAÇÕES: ARX Promoções e Eventos

Telf.: (0xx85) 272-1572 - Fax: (0xx85) 272-7795 